\title{
The application of thin-walled integral constructions in aviation as exemplified by the SAT-AM project
}

\author{
Pawel Bałon ${ }^{1,2^{*}}$, Andrzej Świątoniowski ${ }^{2}$, Bartłomiej Kiełbasa ${ }^{1}$, Edward Rejman ${ }^{3}$, Janusz \\ Szostak ${ }^{2}$, Robert Smusz ${ }^{3}$, and Lukasz Kowalski ${ }^{2}$ \\ ${ }^{1}$ SZEL-TECH Szeliga Grzegorz, Sołtyka 16, 39-300 Mielec, Poland \\ ${ }^{2}$ AGH University of Science and Technology, Department of Manufacturing Systems, Mickiewicza \\ Avenue 30-B2, 30-059 Kraków, Poland \\ ${ }^{3}$ Rzeszów University of Technology, Powstańców Warszawy St. 3, 35-959 Rzeszów, Poland
}

\begin{abstract}
The high level of durability and reliability is a strict requirement for today's aircraft constructions. The most important aspect is the mass of the structure which has a decisive influence on both the volatile and technical properties of an aircraft as well as its economical operation. Modern aircraft structures, or more precisely their load-bearing structures, are almost exclusively manufactured as thin-walled ones which meet the requirement to minimize the mass of the structure. While the local loss of coverage stability is permissible under operating load conditions, exceeding critical load levels of the structural skeleton elements (e.g. frames, stringers) is practically synonymous with some destruction of the structure. It results in a necessity for the continual improvement of both design methods and the improvement of structural solutions of aviation structures. By reducing the thickness of the cover and, at the same time, introducing densely spaced stiffening longitudinal elements, a structure with considerably higher critical loads can be obtained and, consequently, a more favorable distribution of gradients and stress levels which directly contributes to an increase in fatigue life. This paper attempts to analyze the above-mentioned problem more closely, using the example of a densely ribbed rectangular plate.
\end{abstract}

\section{Introduction}

Aviation structures are subject to a wide spectrum of loads during operation. Each task performed during a flight consists of a number of maneuvers that generate different types of aircraft load, both in value and direction of their action. High durability and reliability are strict requirements for modern aviation constructions.. Such requirements result in the fact that many restrictions must be taken into account during the aircraft design process. The most important element is the mass of the structure, which has a decisive impact on both flight and technical properties, as well as economic efficiency. All of these factors make aircraft one of the most complex systems of modern technology. 
Modern aviation constructions, or more precisely, load-bearing structures, are made almost exclusively as thin-walled ones to fulfil perfectly the postulate of minimizing the structure's mass. Such structures, in which the cover is reinforced with longitudinal and transverse elements, thus providing the whole system with the required rigidity and strength, are common. Local loss of coverage stability is permissible only under the conditions of a service load, however exceeding the critical load levels of the skeleton body components (frames, longerons) is virtually synonymous with structural damage. This specificity forces a continual improvement of both design methods and solutions for aviation structures. The development of materials science and a continual improvement of technological processes is critical for effectiveness in applying these ideas. These disciplines foster the design of geometrically complex integral structures that create opportunities not only for a more rational use of material characteristics, but also by appropriate shaping, increase significantly the mechanical properties of the supporting structure. Economic savings, gained as a result of elimination or reduction of assembly operations, are an advantage of primary importance in favor of the use of integral constructions. The category of load-bearing structural elements which, while reducing weight, increase the strength parameters of the load-bearing structure, includes densely ribbed cover elements. By simultaneously reducing the thickness of the covering and introducing densely arranged stiffening longitudinal elements, a structure with significantly higher critical load values can be achieved, and this results in a more favorable distribution of gradients and stress levels, which leads, in turn, to an increase of the structure's fatigue life.

\section{Methods of the thin-walled structures strength increase}

Thin-walled load-bearing aircraft structures are subject to complex loading conditions resulting from a wide array of aircraft operations. In order to meet the requirements of the system in accordance with the relevant regulations, they must possess adequate rigidity and strength. Presented below are a few ways to achieve this goal:

- the use of a thick coating, which leads to an increase in the weight of the structure and inefficient use of material properties,

- the use of composite structures (including sandwich ones), which is connected with the necessity of using ATL technology ensuring repeatability of mechanical properties of the structure (thin- layer pre-impregnates laid in layers or sets of layers using the innovative Automatic Tape Laying technology),

- strengthening the coverage with stiffening elements. This solution is currently widely used asit allows the efficient use of material and properties of the geometry of the structure.

The choice of method depends on many factors, one of the most important being the load level at which the structure experiences a loss of local stability in the covering elements.

\section{Work of compressed rectangular plate reinforced with longerons}

One of the elements of the airframe bearing structures designed nowadays is a structure consisting of a thin-walled covering and stiffening longitudinal and transverse elements. One of the dominant forms of load is compression caused by an evenly distributed continuous load applied to the edge of the slab, parallel to the longitudinal axis (Fig. 1). 


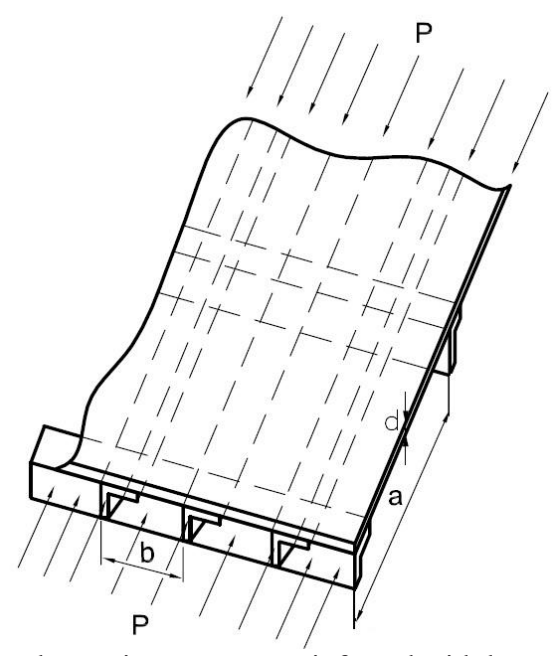

Fig. 1. Diagram of the compressed covering structure reinforced with longerons and frames

The system coverage, reinforced with longitudinal and transverse elements, is divided into a number of elements, each of which, when isolated, can be treated as a supported plate (usually articulated) on four edges. The successively increased load causes the stress states shown in Figures 2-4. When $\mathrm{P}<\mathrm{Pkr}$, then the cover does not lose stability and in the whole area of the plate a homogeneous stress state appears:

$$
\sigma_{\text {longeron }}=\sigma_{\text {av air akin }}=\frac{P}{\sum A_{\text {longeron }}+A_{\text {av air skin }}}
$$

An increase in the the load leads to the appearance of a critical condition. After crossing the threshold, the structure takes a curvilinear geometric form, which significantly changes the stress state of the structure. The individual stages of stress change are shown in the diagrams below.

$$
\sigma_{c y}=\sigma_{\text {longeron }}=\sigma_{\text {aV air skin }}=\sigma_{\text {max air skin }}
$$

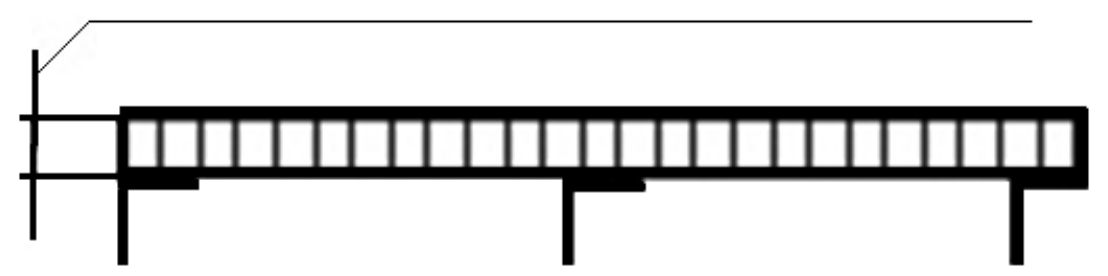

Fig. 2. Stress state in a compressed slab before loss of stability

An increase of the force $\mathrm{P}$ causes a growth in stress in the longerons and covering elements near longerons that have not lost stability. In the elements that have lost stability, stress remains at the $\sigma \mathrm{KR}$ level. 


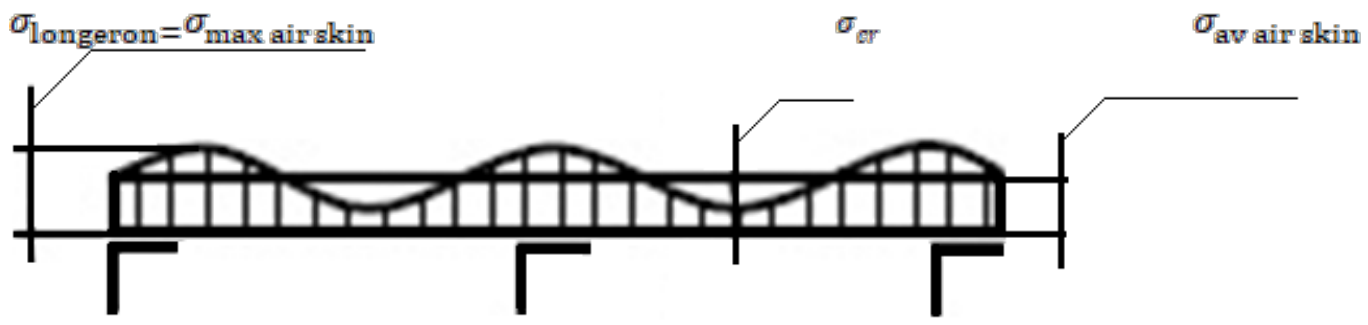

Fig. 3. Stress state in the plate cross-section after loss of stability

At a certain level of the force $\mathrm{P}$, it will increase so much that the stresses in the longerons and the adjacent coverage areas will become equal to the boundary- limiting stress that the longerons can transfer. These elements subsequently lose stability as well and the plate is destroyed.

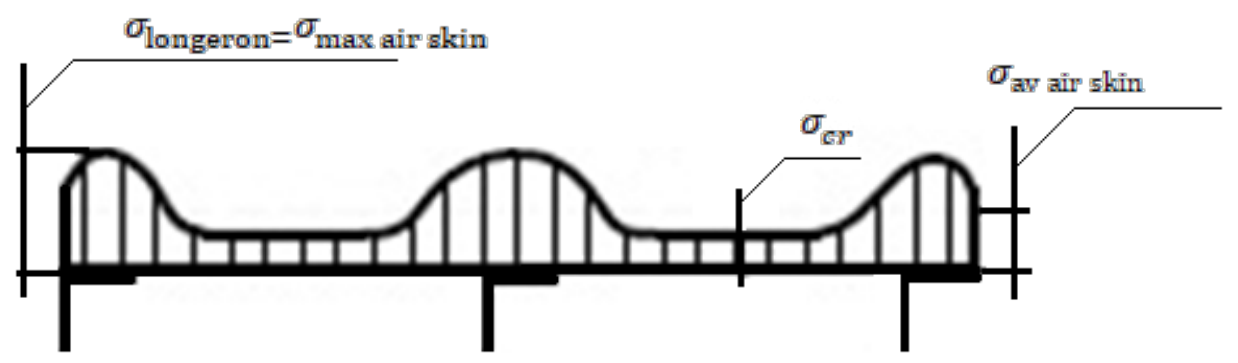

Fig. 4. Stress distribution in the cross-section of a ribbed plate for limiting bearing capacity

\section{Technological methods of increasing the load capacity of aircraft structures and reducing their mass}

The use of integral structures allows for reduction of the structure's weight and the workload of their implementation as it avoids the use of connecting elements and local redimensioning of the structure. However, this entails the introduction of technologies which enable the formation of thin-walled, load-bearing elements. In modern aviation, integral parts of aircraft made of aluminium and titanium alloys are most often shaped by machining from semi-finished products, such as cold-rolled or hot-rolled plates.

In addition, chipless surface forming is also used, which improves the properties of the surface layer of the element. The continuous efforts to reduce production costs in the aviation industry has forced the creation of new methods and strategies for the machining of airplane and helicopter structural components by introducing integral elements. Structural elements of an aircraft in the past decade were usually sheet metal constructions, riveted with a small addition of composite materials. The assembly units contained a large number of parts which increased the workload and weight of the structure. This can be improved by application of the High Speed Machining (HSM) method which enables the 
implementation of integral thin-walled structures from full fabrications. The use of HSM enabled the production of elements such as the aircraft frame as one integral part instead of a unit consisting of 30 or more parts (Fig. 5).

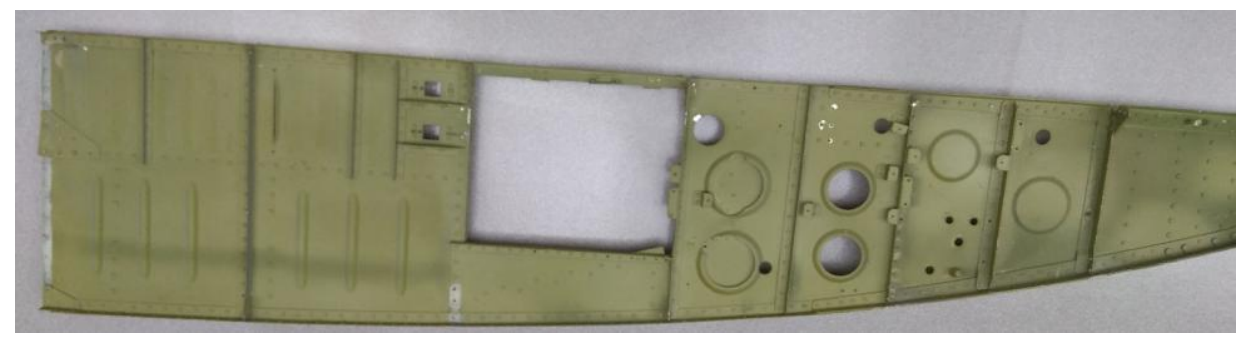

Fig. 5. Plane beam made with the technology of bending and riveting sheet metal structures

HSM enables the production of integral elements, while maintaining such important features of aircraft structures as low weight and thin walls ensuring adequate strength and high rigidity. An important issue when using HSM, especially in roughing thin walls and ribs, is the proper distribution of machining allowance to ensure proper flexural rigidity, which affects machining accuracy and surface roughness. In order to obtain adequate machining efficiency as well as surface quality and dimensional accuracy of the elements manufactured, it is necessary to conduct machining at high cutting speeds and high spindle speeds. The research was carried out at a cutting speed vc of approx. $850 \mathrm{~m} / \mathrm{min}$ and a rotational speed of the tool $\mathrm{n}=48,000 \mathrm{rpm}$. To obtain adequate process efficiency, a relatively small depth of cut (less than $1.5 \mathrm{~mm}$ ) was used, which in turn caused low cutting forces as well as small dimensional and shape deformations of the workpiece. In the research conducted, it was found that when finishing walls with a thickness of less than 1.5 $\mathrm{mm}$, to obtain adequate accuracy, an important factor was the width of the cutting layer ap measured along the milling axis, which should not exceed $6 \mathrm{~mm}$ for walls up to $75 \mathrm{~mm}$ high. When finishing a corner treatment, if the ratio of wall height to corner radius is large:

- use a tool with the largest possible diameter (smaller L / D ratio)

- use a smaller diameter tool for final machining.

When making parts with a wall thickness of approx. $0.6 \mathrm{~mm}$, it is recommended to use diamond tools as they may enable attainment of a machined surface with roughness $\mathrm{Ra}$ approx. $0.2 \mu \mathrm{m}$ and reduction of vibrations which, in turn, might lead to deterioration of the surface wave and damage of the tool. Diamond tools are characterized by low wear and ensure adequate surface quality for long-term treatment. The key criterion for the selection of cutting parameters, in addition to ensuring adequate surface roughness and dimensional and shape accuracy, is obtaining appropriate machining efficiency. It can be measured using the MMR (Material Removal Rate), which will determine the propriety of using the HSM method for a given part.

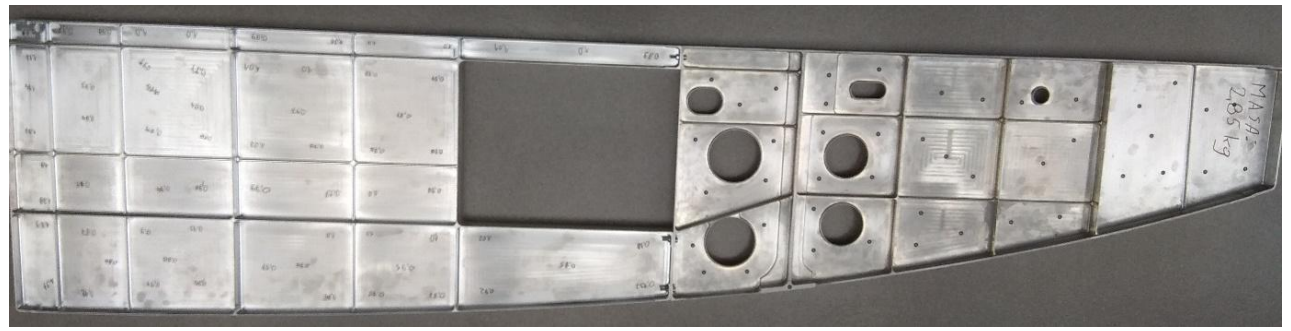


Fig. 6. Aircraft beam (thin-walled structure) made using HSM milling technology

In order to show the applicability of HSM technology in aircraft constructions, the aircraft beam shown in Figure 5 (classic technology) was made using this method, which is presented in Figure 6. This subassembly was installed interchangeably in the aircraft fuselage and it meets all construction and assembly requirements. Our own research confirmed the risk of vibrations due to inappropriate selection of cutting parameters or incorrect machining strategy, especially due to the selection of the machining path of the tool. Most often in such cases technologists try to reduce the spindle speed. According to the authors' assessment, better results can be obtained by properly defining the form of the blank so that its shape and dimensions are as close as possible to the dimensions of the finished part. The tool path during finishing, especially when machining large flat surfaces, should be shaped so that the machining allowance is removed first near the center of the plate, and finally at its periphery. HSM (High Speed Machining) is commonly used in the aviation industry, especially when used for machining aluminium alloys [1,2]. The factor distinguishing HSM from other milling techniques is such a wide selection of cutting parameters - milling width, depth of cut, feed, and cutting speed - which ensures good surface quality, accuracy of dimensions and shapes of the workpiece, as well as high machining efficiency to shorten the process of manufacturing integral parts. This is described in the following formula, where: $a_{e}$ - is cutting layer width [mm], $a_{p}$ - cutting depth $[\mathrm{mm}]$,

$$
Q=\frac{a_{e} * a_{p} * V_{f}}{1000}\left[\frac{\mathrm{cm}^{3}}{\min }\right]
$$

The introduction of the HSM method enables the manufacture of very complex integral thin-walled aviation parts from solid material. In designing the structure of an aircraft, the current tendency is to make them primarily of integral elements, which in previously used technologies were produced by joining components using welds or rivets. These components include ribs, stringers, girders, and frames, as well as fuselage and wing covers. After milling these parts are assembled into larger units or complete products. The main purpose of these procedures, in addition to ensuring compliance with the functionality criterion, is to obtain the best strength to weight ratio of the structure.

The use of high machining speeds enables cost-effective production of integral parts by reducing machining time, but also improves the quality of the machined surface as the cutting forces are much smaller than those employed in classic processing methods $[3,4]$. One of the key factors determining the introduction of the HSM method in the aviation industry is the efficiency of the cutting process Q [ $\mathrm{mm} 3 / \mathrm{min}]$, depending on the cutting depth ap, width of the cutting layer ae, feed per tooth $\mathrm{f}_{\mathrm{z}}$, number of tool blades $\mathrm{zn}$ and tool speed $n$. An application of excessive cutting parameters, especially feed and depth of cut, causes the occurrence of an unfavorable phenomenon known as self-excited vibrations. 


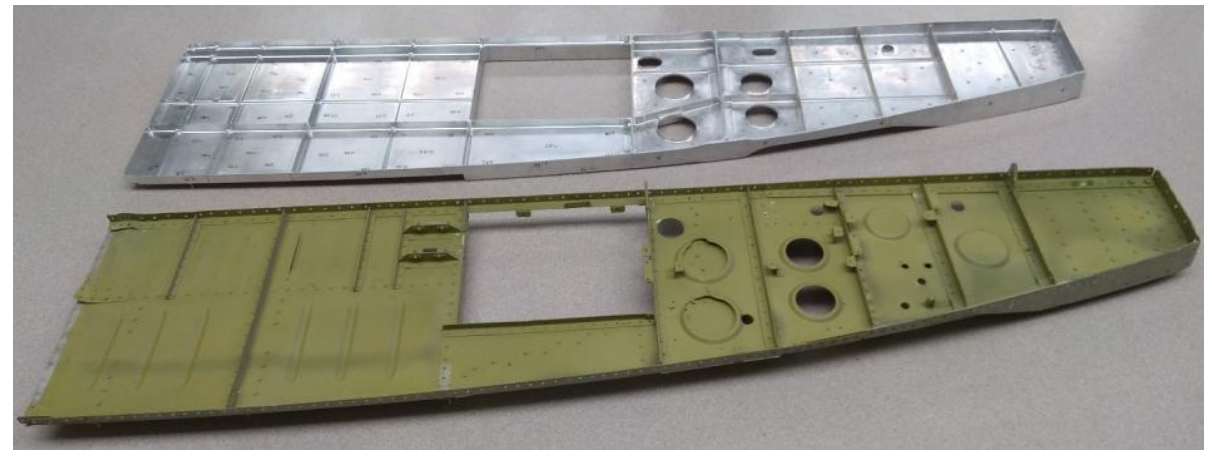

Fig. 7. Plane beam made using profile bending technology and HSM milling

The ranges of acceptable, stable machine tool operation are presented by means of the so-called saddle curve showing the dependence of the depth of cut on the rotational speed of the tool for the other determined process parameters.

The correct selection of cutting parameters ensures the wavy finish which is acceptable and expected for this class of products. The use of rapid milling for both roughing and finishing reduces significantly machining times, which is an important economic aspect $[4,5]$. To compare the results of our own research, Figure 7 shows the aircraft structural beam made using classic technology and with HSM milling technology.

\section{Technological recommendations for the application of HSM technology in the formation of aircraft structures}

High-speed milling ensures that complex thin-walled parts are made of block in accordance with the stringent requirements for product quality, as well as shortening the manufacturing time and avoiding costly tooling used in other technologies.

The use of HSM milling facilitates the implementation of thin walls because it reduces the contact time of the tool with the workpiece and, consequently, reduces the force and thermal factors that cause elastic and plastic deflections. Plastic deformations can be a source of natural stress in the surface layer, causing deformation of the workpiece after processing. It increases production costs resulting from defects, extension of production time, and material costs. In the aerospace industry, light metal parts are made by removing up to $98 \%$ of the stock material by milling. Rapid milling penetrates other industrial fields ; it is more often used in the automotive industry to manufacture parts from aluminium or magnesium alloys. In the production of molds and dies in finishing processing, a low surface roughness is obtained, which minimizes or eliminates manual processing (polishing). High speed machining was first utilized in milling, but was also adapted to turning, boring, and drilling. Modern machine tools are multi-tasking, the result of several complex operations being carried out in one operation.

The research conducted on the application of HSM technology in the implementation of thin-walled structures made possible the formulation of certain techniques which led to the minimizing of shape errors and improving the surface quality of machined parts: - a cutting speed of $850 \mathrm{~m} / \mathrm{min}$ should be used: for walls with a thickness of $0.6-1 \mathrm{~mm}$, cutting speeds of approx. $1000 \mathrm{~m} / \mathrm{min}$ and cutting depth of approx. $0.2 \mathrm{~mm}$ are appropriate, - the cutting parameters should be optimized due to the cutting force component being perpendicular to the milled wall, 
- the basic condition for the correct processing of thin-walled structures, guaranteeing good surface quality and maintaining shape tolerance, is the selection of the appropriate heightthickness ratio, namely:

- for very thin walls - the ratio of height to thickness should be $<15: 1$

- for walls of moderate thickness, the height to thickness ratio should be $<30$ : 1

- for thick walls, the ratio of height to thickness may be greater than 30: 1.

- the structure should include both transverse and longitudinal stiffeners, although their thicknesses may vary (Fig. 8).

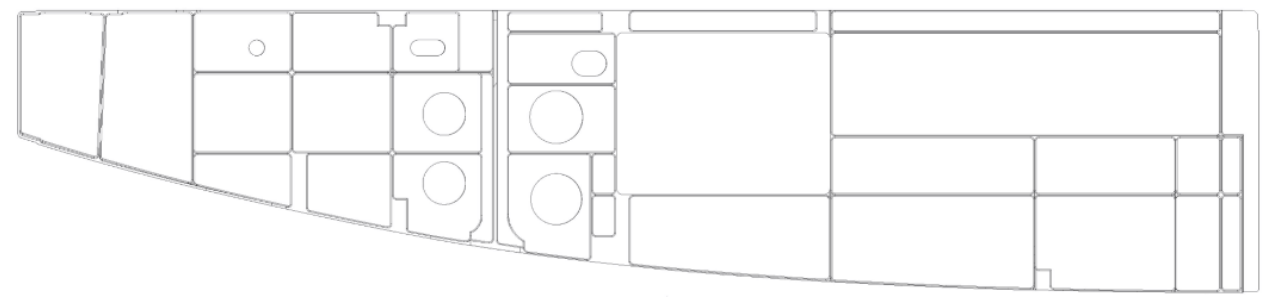

Fig. 8. Airplane beam geometry with transverse and longitudinal stiffeners

The number of passes in all cases will depend on the wall dimensions and axial depth of a cut. In order to reduce wall deflection during machining, it was necessary to shorten the tool's contact time with the workpiece by using a high rotational speed. The stability of the tool and the processed wall plays an important role. For low-rigidity support of the thinwalled piece, out-cut milling should be used. The effects can also be improved by milling the opposite sides of the rib while maintaining the difference in milling levels, which guarantees better wall support at the points where the milling depth changes. It is recommended that the finishing allowance be 0.2 to $0.5 \mathrm{~mm}$. For walls with low thicknesses $(0.4-0.6 \mathrm{~mm})$ and high surface quality requirements, it is advisable to use auxiliarymounted high-speed electrospindles on machine tools and to use a shallow cutting depth. The range of applications for HSM technology is currently expanding significantly beyond the aviation industry and it is increasingly used in other industries, as shown in Table 1.

Table 1. The scope of application of HSM technology in modern industry [9].

\begin{tabular}{|l|l|l|}
\hline $\begin{array}{l}\text { Technological } \\
\text { benefits }\end{array}$ & $\begin{array}{l}\text { Range of } \\
\text { applications }\end{array}$ & $\begin{array}{l}\text { Examples of } \\
\text { industrial } \\
\text { applications }\end{array}$ \\
\hline $\begin{array}{l}\text { High } \\
\text { volumetric } \\
\text { machining } \\
\text { efficiency }\end{array}$ & $\begin{array}{l}\text { Light alloys, } \\
\text { steels, and cast } \\
\text { iron }\end{array}$ & $\begin{array}{l}\text { Production in the } \\
\text { aerospace industry, } \\
\text { manufacture of } \\
\text { foundry tools and } \\
\text { molds }\end{array}$ \\
\hline $\begin{array}{l}\text { High surface } \\
\text { quality }\end{array}$ & $\begin{array}{l}\text { Precision } \\
\text { machining, } \\
\text { special elements }\end{array}$ & $\begin{array}{l}\text { Optical industry, } \\
\text { precision mechanical } \\
\text { parts, spiral blades for } \\
\text { compressors }\end{array}$ \\
\hline $\begin{array}{l}\text { Low cutting } \\
\text { forces }\end{array}$ & $\begin{array}{l}\text { Machining of } \\
\text { thin-walled } \\
\text { elements }\end{array}$ & $\begin{array}{l}\text { Aerospace industry, } \\
\text { automotive industry, } \\
\text { household industry }\end{array}$ \\
\hline $\begin{array}{l}\text { High excitation } \\
\text { frequencies }\end{array}$ & $\begin{array}{l}\text { Wherever } \\
\text { machining is } \\
\text { impossible due } \\
\text { to achieving }\end{array}$ & $\begin{array}{l}\text { Precision mechanics } \\
\text { and the optical } \\
\text { industry }\end{array}$ \\
\hline
\end{tabular}




\begin{tabular}{|l|l|l|}
\hline & $\begin{array}{l}\text { critical vibration } \\
\text { frequencies }\end{array}$ & \\
\hline $\begin{array}{l}\text { Cutting heat } \\
\text { transport by } \\
\text { chips }\end{array}$ & $\begin{array}{l}\text { Materials } \\
\text { processing with } \\
\text { particular } \\
\text { limitation } \\
\text { onheat influence }\end{array}$ & $\begin{array}{l}\text { Precision mechanics, } \\
\text { magnesium alloys }\end{array}$ \\
\hline
\end{tabular}

\section{Conclusions}

The use of High Speed Milling technology for machining of thin-walled aircraft frames is possible due to the precision of the workpiece and the machining capabilities of the 7075 aluminium alloys. An appropriate cutting parameter selection ensures good surface roughness and waviness.

In the case of the machined wall having a height-thickness ratio of less than 15 , the influence of the structural deformation on the workpiece's dimensional precision is unimportant and falls within the tolerances of the milling machine. For the thickness of larger walls, this influence starts to become visible and needs to be minimized through cutting speed selection (feed rate, cutting depth).

Providing dimensional-shape precision during machining requires an appropriate selection of the technological bases and the mounting method of the workpiece. In compound spatial structures, some additional bases ensuring mounting stiffness should be utilized and then removed during final operations.

The final HSM technology application allows the producer to reduce the workpiece machining time. The manufacturing time for the frame (including software preparation) is 320 hours. This can be reduced to 15 hours in the series production by using the proven control program and the experience gained during prototype manufacturing. The roughing time of the frame is about 18 hours, and the finishing takes about 5 hours, which comes to about 23 hours to manufacture the frame using HSM technology. When comparing the HSM method to conventional machining methods, it should be noted that 141 hours are needed to manufacture the frame by conventional milling.

The completed part is an integral construction replacing the current methods of manufacturing the same element by plastic processing of individual parts ( 30 or more parts) and then joining them with fasteners. The total manufacturing time for individual elements of the frame was over 6 times the hours needed using the recommended HSM method. Along with the benefits resulting from the reduction of the manufacturing time for the frame, a substantial benefit of the proposed technology is also the quality and precision of the manufacturing, as well as the roughness class of the surfaces.

These works were carried out within the project "699757/SAT-AM" - Work programme topic: JTI-CS2-2015-CPW02-AIR-02-07. More Affordable Small Aircraft Manufacturing; Airframe; Grant Agreement No: CS2-AlR-GAM-2014-2015-01 (annex III) co-financed by Horizon 2020 Clean Sky 2. Special thanks go to the teams from: Instytut Lotnictwa, SZEL-TECH Szeliga Grzegorz, Zakłady Lotnicze Margański\&Mysłowski, PZL Mielec, CIRA, Eurotech, Metrol, and Ultratech. 


\section{References}

1. M. Lundblad, Influence of Cutting Tool Geometry on Residual Stress in the Workpiece, Proc. Third Wave Advant Edge User's Conferece, Atlanta, GA, Paper 7 (2002)

2. C. Shet, X. Deng, Residual Stresses and Strains in Orthogonal Metal Cutting, Int. J. Machine Tools Manuf., 43/6, 573-587 (2003)

3. A.J. Shih, H.T.Y. Yang, Experimental and Finite Element Predictions of Residual Stresses Due to Orthogonal Metal Cutting, Int. J. Num. Meth. Eng., 36, 1487-1507 (1993)

4. W. Adamski, Manufacturing development strategies in aviation industry, Advances in Manufacturing Science and Technology, Vol. 34, nr 3, 73-84 (2010)

5. P.T. Mativenga., K.K.B. Hon, An experimental study of cutting force in high speed end milling and implications for dynamic force modelling, Journal of Manufacturing Science and Engineering, 127, 2, 251-261 (2005)

6. J. Kuczmaszewski,P. Pieśko, M. Zawada-Michałowska, Influence of Milling Strategies of Thin-walled Elements on Effectiveness of their Manufacturing, Procedia Engineering, 182:381-186 (2017)

7. P. Bałon, J. Szostak, B. Kiełbasa, E. Rejman, R. Smusz, Application of High Speed Machining Technology in Aviation, $21^{\text {st }}$ International ESAFORM Conference on Material Forming (2018)

8. P. Bałon, E. Rejman, R. Smusz, J. Szostak, B. Kiełbasa, High Speed Milling in thinwalled aircraft structures, Applied Computer Science Volume 14, Number 2, pp. 8295 (2018)

9. Wit Grzesik, Advanced Machining Processes of Metallic Materials, Elsevier, 2016 